\title{
Cathode Heater Compensation as Applied to Degen- erative Voltage-Stabilized Direct-Current Power Supplies
}

\author{
By Robert C. Ellenwood and Howard E. Sorrows
}

\begin{abstract}
A new method of compensating a degenerative-type voltage stabilizer that simplifies the design of precision stabilized direct-current power supplies is discussed. If the operating voltages of the direct-current amplifier in the comparator circuit of the stabilizer are properly chosen, compensation for line voltage changes is obtained from the corresponding changes in the "heater-to-plate transconductance." An equation for the over-all stabilization factor of the compensated stabilizer is presented in terms of the stabilization factor of a simple degenerative stabilizer. Output voltage changes of less than 0.005 percent for \pm 10 -percent change in line voltage were obtained from experimental tests of sample power supplies with 350 volts output.
\end{abstract}

\section{Introduction}

To improve the accuracy of ultrahigh frequency measurements, it was found expedient to develop several precision stabilized d-c power supplies [1]. ${ }^{1} \quad$ Although each power supply was designed for use with a specific instrument, it was required that each:

1. Produce the required d-c output of several hundred volts.

2. Be designed for a current drain of several hundred milliamperes with an approximately constant load resistance.

3. Have stability such that the output voltage be practically independent of line voltage changes expected in the laboratory.

4. Have as simple a circuit as possible to facilitate repairs and adjustments.

Neher and Pickering, in a 1939 report [2], observed that under certain conditions the experimental performance of a stabilized power supply was better than their theoretical prediction. They found that the lower the screen grid voltage of one of the component tubes, the better the voltage stabilization. This phenomenon could be attrib-

\footnotetext{
${ }^{1}$ Figures in brackets indicate the literature references at the end of this paper.
}

uted to the greater cathode temperature control of the amplifier-tube plate current at lower screen voltages. Since the cathode temperature depends on the heater voltage, the variations in heater voltage can be employed to improve the voltage stabilization for variations in line voltage.

In view of the disagreement in literature in the usage of the terms "regulation" and "stabilization", it is desirable to define these terms as used in this paper. Stabilization refers to the reduction of output voltage or current fluctuations. Regulation refers to the percentage change of output voltage of a power supply as the powersupply output current is changed.

\section{General Theory and Design Considera- tions}

The majority of commercially available generalpurpose stabilized power supplies that furnish several hundred milliamperes at several hundred volts are of the degenerative amplifier type. The basic circuit of this type of stabilizer is shown in figure 1. The degenerative $\mathrm{d}-\mathrm{c}$ amplifier $\left(T_{2}\right.$ in fig. 1) is in a comparator circuit [3] that compares the output voltage of the stabilizer with some reference voltage. The over-all stability of the 
power supply is no better than the stability of the reference voltage. Dry cells or standard cells can be used as precision reference-voltage standards. VR tubes are too unstable for reference voltages when precision stabilization is desired [4].

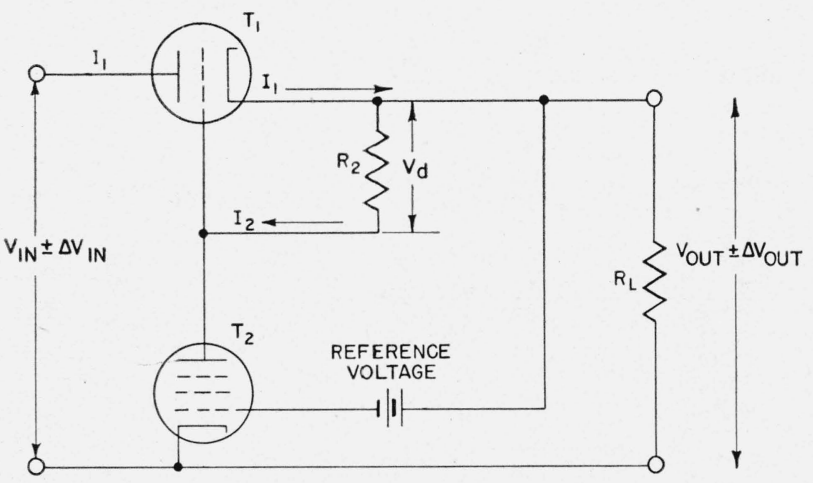

Figure 1. Simplified degenerative-voltage-stabilizer schematic.

The equation of stabilization for figure 1 is usually given as follows:

where

$$
F=1+\frac{r_{p 1}}{R_{L}}+\frac{R_{2} \mu_{1}\left(\mu_{2}+1\right)}{r_{p 2}+R_{2}},
$$

$$
\begin{aligned}
F= & \text { stabilization factor }\left(\Delta V_{\text {in }} / \Delta V_{\text {out }}\right) . \\
\Delta V_{\text {in }}= & \text { change in d-c voltage input to stabil- } \\
& \text { izer. } \\
r_{p 1}= & \text { plate resistance of the control tube } \\
& \left(T_{1}\right) . \\
R_{L}= & \text { external load resistance. } \\
R_{2}= & \text { plate load resistance of d-c amplifier } \\
& \left(T_{2}\right) . \\
\mu_{1}= & \text { amplification factor of the current } \\
& \text { control tube }\left(T_{1}\right) . \\
\mu_{2}= & \text { amplification factor of the d-c ampli- } \\
& \text { fier }\left(T_{2}\right) .
\end{aligned}
$$

It is seen from the above equation that the theoretical stabilization factor $(F)$ for a given load $\left(R_{L}\right)$ is limited by the amplification factors and the plate resistances of the given tubes. It is noted that the stabilization factor (eq 1) does not directly consider the effect of line voltage changes on the heater voltage. The heater voltage is proportional to the line voltage in most power supplies.

Precision measurements often require the use of a d-c power supply with output voltage practi- cally independent of line voltage changes. A stabilization factor $\left(F_{L}\right)$, which includes the effect of variations in the line voltage on the heater voltage, is given in eq 2 , in terms of the stabilization factor $(F)$ of eq 1 .

$$
F_{L}=\frac{F}{N_{p}\left(1-\frac{R_{2} \mu 1 r_{p 2} S_{h 2} N_{h}}{r_{p 2}+R_{2}}\right)},
$$

where

$$
F_{L}=\frac{\text { Change in line voltage }\left(\Delta V_{L}\right)}{\text { Resultant change of output voltage }\left(\Delta V_{\text {out }}\right)} \cdot
$$

$N_{p} \approx$ Turns ratio of plate transformer.

$N_{h} \approx$ Turns ratio of heater transformer.

$S_{h 2}=\Delta i_{p 2} / \Delta e_{h 2}=$ heater-to-plate transconductance.

The term "transconductance" is used for want of a better term to describe the effect on the plate current of heater voltage acting through its control upon the initial velocity of the electrons emitted by the cathode. Although the expression is dimensionally correct, no attempt is made to defend it as rigorously correct. It is evident from eq 2 that, if the denominator equals zero, $F_{L}$ approaches infinity, which indicates perfect stabilization with respect to line voltage changes. If the other factors in the denominator are of the proper order of magnitude, nearly perfect stabilization can be obtained by adjusting the heater to plate transconductance $\left(S_{h 2}\right)$ of the d-c amplifier tube $\left(T_{2}\right)$. Therefore, the design of a heatercompensated power supply requires a family of characteristic curves for the d-c amplifier tube ( $T_{2}$ of fig. 1) that presents the plate current as a function of heater voltage and screengrid voltage.

\section{Description of Operation}

Measurements were made on the stabilized power supply shown in figure 2 for the purpose of analyzing its heater compensation. It was found that the output voltage is sensitive to small changes in the heater voltage of the d-c amplifier tube $\left(T_{2}\right)$ but independent of the heater voltage of the control tube $\left(T_{1}\right)$.

Since the compensation is effected through the d-c amplifier tube, $T_{2}$, a study was made of the operation of the amplifier curcuit. When a change occurs in the heater voltage, the change in the plate current of the amplifier tube results in a proportional change in the voltage $V_{d}$ across $R_{2}$, which appears on the grid of the control tube $T_{1}$. 


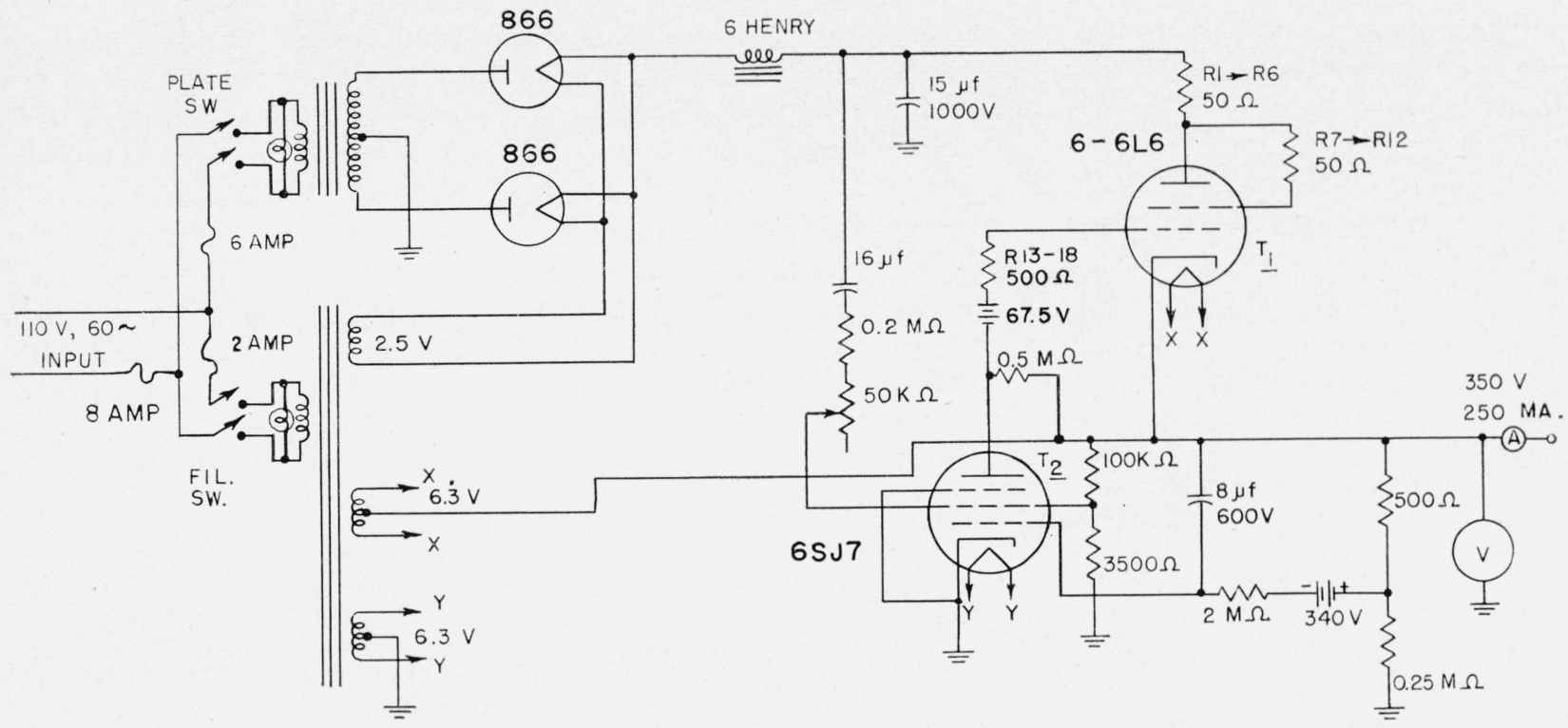

Figure 2. Heater-compensated power supply, 350-v d-c,250 ma.

In this way additional compensation for a line voltage change can be obtained from the heater voltage change. The change in voltage $V_{d}$ per $20-\mathrm{v}$ change (100 to $120 \mathrm{v}$ ) in line voltage was measured for various values of screen voltage. It was found that the lower the screen voltage, the greater the incremental change in the voltage drop per unit change in heater voltage (See fig. 3).

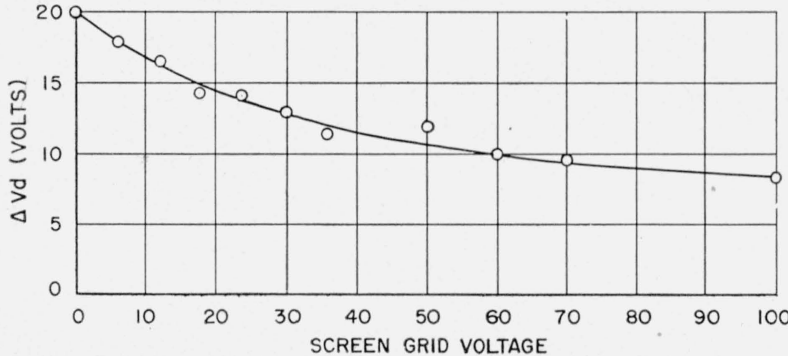

Figure 3. Change in voltage drop across resistor $\left(R_{2}\right)$ for 20-v change in a-c line voltage ver sus screen-gridvoltage.

As the heater-to-plate transconductance, $S_{h 2}$ in eq 2 , is defined as the change in plate current per unit change in heater voltage with all other tube voltages held constant, it is seen that the incremental change in the voltage drop per unit change in heater voltage, the ordinate of figure 3 , is proportional to $S_{h 2}$. Therefore the transconductance, $S_{h 2}$, varies with the screen-grid voltage as in figure 3. The screen-grid voltage, at which $S_{h 2}$ has the proper value for maximum stabilization, can be selected from experimental data such as is shown in figure 4 .

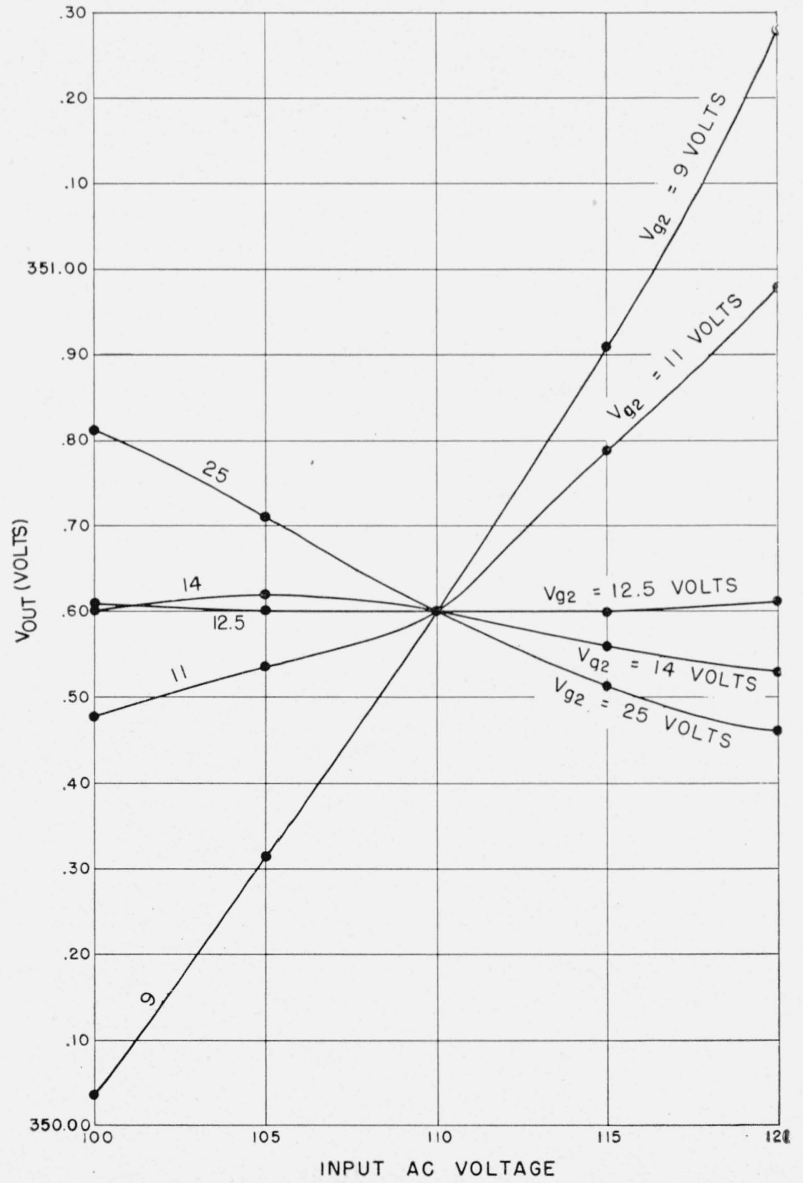

Figure 4. Stabilized d-c output voltage for various screen grid voltages. 
The improvement with heater compensation of the stabilization of a power supply is shown in figure $5, \mathrm{a}, \mathrm{b}$, and $\mathrm{c}$. The performance of the
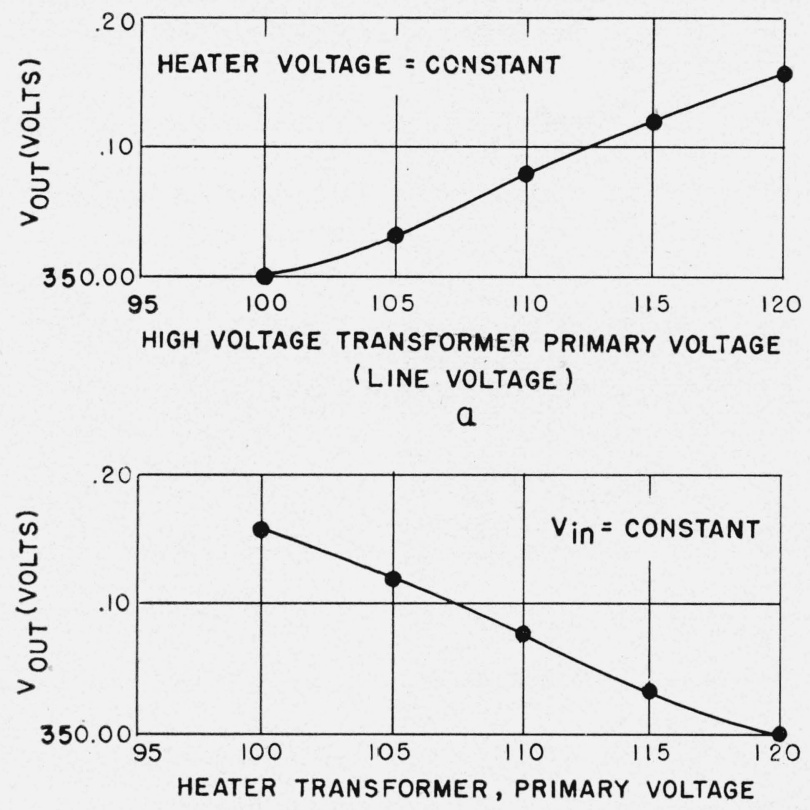

b

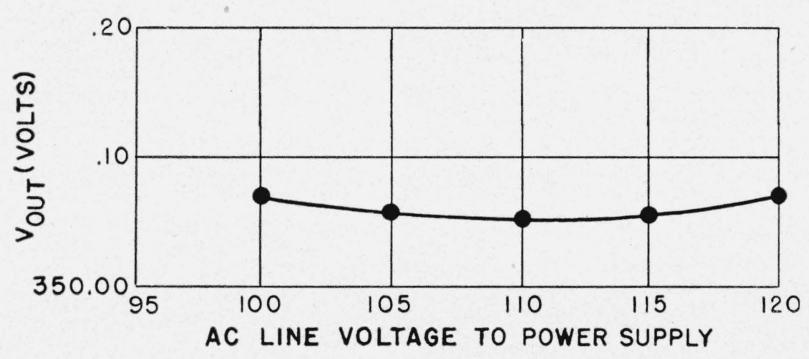

C

Figure 5.

a, Stabilized d-c output voltage versus primary voltage of high-voltage transformer; b, stabilized d-c output voltage versus primary voltage of heater transformer; c, stabilized d-c output voltage versus a-c line voltage.

power supply without heater compensation is shown in figure 5 , a. It is seen that with a constant heater voltage an increase in line voltage of $10 \mathrm{v}$ resulted in an increase in output voltage of about $0.1 \mathrm{v}$. The effect of changes in heater voltage is presented in figure $5, \mathrm{~b}$. With the input voltage to the stabilizer, $V_{\text {in }}$, held constant and the screen grid voltage set at the value for maximum stabilization, an increase of $10 \mathrm{v}$ in the primary voltage of the heater transformer resulted in a decrease in the output voltage of about $0.1 \mathrm{v}$. Thus it is seen that the heater voltage can be employed to provide the additional compensation that the degenerative-type voltage stabilizer usually lacks for perfect stabilization with respect to line voltage changes. Figure 5, c shows that, with the primaries of the high voltage and heater transformers connected to a common line voltage and the screen grid voltage set at its proper value, the heater-compensated power supply has a maximum deviation of output voltage of $0.01 \mathrm{v}$ for a line voltage change of \pm 10 percent. This is a variation of less than 0.0005 percent in output voltage per volt change in the line. The performance appeared to be unaffected by changing from one amplifier tube $\left(T_{2}\right)$ to others of the same kind, and over the period of time the power supply was used there appears to be no effect from aging.

The following measurements were obtained from the sample power supply (fig. 2):

\begin{tabular}{|c|c|}
\hline Parameter & Measured value \\
\hline Output voltage $\ldots \ldots$ & $350 \mathrm{v} d-\mathrm{c}$ \\
\hline Input voltage to stabilizer_ & $550 \mathrm{v}$ d-c \\
\hline $\begin{array}{l}\text { Amplifier screen-grid volt- } \\
\text { age. }\end{array}$ & $12.5 \mathrm{v} d-\mathrm{c}$ \\
\hline $\begin{array}{l}\text { Amplifier control-grid volt- } \\
\text { age. }\end{array}$ & $-0.95 \mathrm{v} \mathrm{d}-\mathrm{c}$ \\
\hline Output ripple & $1.9 \mathrm{mv}(\mathrm{rms})$ \\
\hline Internal resistance & 2 ohms \\
\hline $\begin{array}{l}\text { Over-all stabilization fac- } \\
\text { tor }{ }^{2}\end{array}$ & \\
\hline Percent voltage change ${ }^{b}$ & $\begin{array}{l}0.003 \text { percent for } \pm 10- \\
\text { percent line voltage } \\
\text { change }\end{array}$ \\
\hline
\end{tabular}

a Stabilization factor is $\left(\frac{\Delta \text { line voltage }}{\Delta \text { output voltage }}\right)$.

b Percent voltage change is $\left(\frac{\Delta \text { output voltage }}{\text { output voltage }}\right)$.

Figure 6 shows the performance of this power supply for a wide range of input voltage.

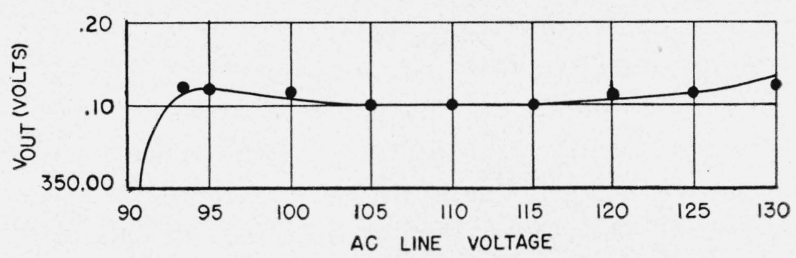

Figure 6. Direct-current output voltage versus line voltage for 12.5 screen-grid volts. 


\section{Compensation for Time Lag}

A compensating voltage determined by the heater voltage of an indirectly heated cathodetype tube has a time lag dependent on the time necessary for the cathode temperature to come to equilibrium $[5,6]$. To reduce the effect of this time lag, an RC circuit is applied between the input terminal ( $V_{i n}$, fig. 1) and the screen grid of the d-c amplifier. When a sudden change of line voltage occurs, the RC circuit applies the proper value of voltage to the screen grid of the d-c amplifier to compensate for the thermal time lag of the cathode temperature. The time constant of the RC network was chosen to be equal to that of the temperature change of the cathode.

\section{Summary}

Heater compensation has been applied to a degenerative voltage stabilizer to obtain a variation of less than 0.0005 percent in output voltage per volt change in line voltage. The high stability was obtained without sacrificing simplicity of design. The amount of compensation from the heater voltage action is a function of the screengrid voltage of the amplifier tube. Experimental methods are given for determining the correct screen-grid voltage for maximum stability.

\section{References}

[1] H. E. Sorrows, R. C. Ellenwood, and W. E. Ryan, National Bureau of Standards, CRPL Report 9-1 (November 8, 1946).

[2] H. V. Neher and W. H. Pickering, Rev. Sci. Instruments 10, 35 (1939).

[3] F. V. Hunt and R. W. Hickman, Rev. Sci. Instruments 10, 6 (1939).

[4] G. N. Kirkpatrick, Proc. Inst. Radio Engrs. 35, 485 (1947).

[5] R. C. Evans, Rev. Sci. Instruments 5, 371 (1934).

[6] J. S. Ashworth and J. C. Mouzon, Rev. Sci. Instruments 8, 127 (1937).

Washington. June 3, 1949. 